\title{
АНАЛИЗ МУЛЬТИМОДАЛЬНЫХ ВЫЗВАННЫХ ПОТЕНЦИАЛОВ В КЛИНИЧЕСКОЙ ПРАКТИКЕ У ПАЦИЕНТОВ С РАССЕЯННЫМ СКЛЕРОЗОМ
}

\author{
Ширалиева Р.К.*, Гусейнова С.К., Несруллаева Н.А. \\ Национальный цееттр офтальмологии им. акад. 3.А. Алиевой, Баку; \\ *Кафедра нервных болезней Азербайджанского Государственного Института Усовер- \\ шенствования врачей им. А. Алиева, Баку
}

Основой патологического процесса при рассеянном склерозе (РС) является демиелинизация, которая ранее считалась необратимой, однако в литературе имеются все увеличивающиеся доказательства процесса ремиелинизации, который происходит в течение определенного периода времени после процесса демиелинизации. Возможность ремиелинизации при РС подтвержается электрофизиологическими методами исследованиями.

Нейрофизиологическое обследование достаточно часто выявляет изменения, протекающие ассимптомно в течении большого периода. Целью данной работы является проведение динамического анализа данных мультимодальных вызванных потенциалов у больных с рассеянным склерозом в 3-х и 6-месячные интервалы в сроки до 3 лет от начала заболевания.

Материалы и методы. Нами проведено комплексное клиническое и нейрофизиологическое исследование 65 больных (43 женщина и 22 мужчин), средний возраст 26,6 $\pm 3,7$ лет. 42 пациента (65\%) поступили с изолированным острым оптическим невритом (ОН), при этом у 9 пациентов(14\%) отмечался двухсторонний ОН. 23 пациента (35\%) - с оптическим невритом на фоне РС. Все пациенты 2 группы на момент обследования находились в стадии обострения заболевания. С целью верификации заболевания проводилось МРТ головного мозга в режимах Т1 и Т2 взвешенных изображений.

Для диагностики патологических состояний использовались электрофизиологиче- ские методы исследования: зрительные вызванные потенциалы (ЗВП) на шахматный паттерн и вспышку, слуховые (АСВП) (ССВП) и соматосенсорные вызванные потенциалы.

При исследовании ЗВП на реверсивный шахматный паттерн применялся разный размер клетки: в 20,30,50 угловых минут. При регистрации латентности и амплитуды пиков Р100 и Р2 во всех отведениях, анализировалась межокулярная разность латентностей.

АСВП регистрировались пиковые латентности: I - ответ от слухового нерва, II ответ от стволового ядра улитки, III - ответ от ядра верхней оливы, IV - ответ от латеральной петли, V - ответ от нижнего двухолмья и межпиковые интервалы: I-III, III$\mathrm{V}, \mathrm{I}-\mathrm{V}$.

Исследование ССВП проводили при электрической стимуляции срединного нерва и анализировали латентности стволового ответа (пик Р13) и кортикального ответа (пик Р21), измеряли время центрального афферентного проведения (ВЦАП) межпиковый интервал Р13-Р21. Электрофизиологические исследования проводились на аппарате "Нейро-ЭРГ" фирмы Нейрософт (Россия).

Результаты. У 42 (65\%) был диагностирован изолированный ОН и у 23 пациентов $(35 \%)$ - рассеянный склероз с оптическим невритом, в то время как при повторном осмотре через 3 года количество тех, кому был поставлен диагноз, рассеянный склероз, увеличилось до 15 (48\%). В период повторных визитов у 9 пациентов были выяв- 
лены новые симптомы ОН в пораженном глазу, у 8 пациентов новые симптомы на парном глазу, у 6 пациентов появились симптомы заболевания, относящиеся к другим участкам ЦНС, ранее бессимптомным. Сканирования МРТ в 78\% показали изменения во время повторных визитов, указывая на распространение старых поражений или образование новых.

Патологическое удлинение латентности P100 на шахматный паттерн в пределах от 112 до 143мкВ отмечалось у 17 больных $(37,7 \%)$, удлинение латентности с изменением верхушки пика P100 W - видной формы, что говорит о грубом нарушении проводимости зрительного нерва у 13 больных $(28,8 \%)$. Патологическое снижение амплитуды ответа у 9 больных (20\%). В последних случаях латентность была в пределах нормы. При исследовании ЗВП на вспышку удлинение латентности Р2 отмечалось в пределах 122- 157 мкВ - у 8 больных (40\%) и снижение амплитуды ответа у 10 больных (50\%). У 2 больных (10\%) на момент обследования ЗВП в пределах нормы. При исследовании ЗВП в фазе клинической ремиссии, сопровождающейся улучшением остроты зрения, выявлена положительная динамика параметров ЗВП в виде достоверного укорочения латентности и амплитуды пиков Р100 и Р2.

При исследовании АСВП у всех пациентов в фазе обострения отмечены удлинение латентных периодов III и V пиков, снижение амплитуды $\mathrm{V}$ пика и тенденция к увеличению межпикового интервала III-V. Выявленные изменения свидетельствовали о нарастании признаков демиелинизации у 30 пациента (47 \%). При обследовании АСВП в 23\% были отмечены признаки ремиелинизации с улучшением параметров пиков и межпикового интервала III-V, в 20 $\%$ случаев АСВП в динамике не претерпевали каких-либо изменений.

При анализе ССВП с срединного нерва у больных РС в фазе обострения выявлено увеличение латентного периода пика Р25 по сравнению с нормой и тенденция к увеличению латентного периода пика N20, также отмечалось достоверное снижение амплитуды пиков N20 и N13, изменение формы ответа определялось у 4-х больных $(6,1 \%)$ в виде слабой дифференцировки пиков N20 и Р25.При повторном исследовании ССВП в фазе клинической ремиссии в $50 \%$, что свидетельствовало о наличии нарастания процесса демиелинизации. В 17\% при повторном обследовании ССВП было отмечено улучшение ответов и признаки ремиелинизации.

При динамическом обследовании АСВП и ССВП, параметры ВП или слабо изменялись, или давали ухудшение, т.е. нарастание демиелинизации. В меньшем \% случаев, по сравнению с динамикой ЗВП, отмечались улучшение параметров и имелись процессы ремиелинизации: соответственно $52 \%$ для ЗВП $23 \%$ для АСВП и только 17\% для ССВП. Т.о. более отчетливые процессы ремиелинизации по данным ВП отмечались при анализе проведения по зрительным путям. Таким образом, в течение первых 3 лет после ОН в зрительном нерве активны два противоположных процесса: с одной стороны, восстановительный процесс ремиелинизации, и с другой стороны, бессимптомно развивающийся процесс демиелинизация и/или дегенерации аксонов. 


\title{
XÜLASə
}

\section{DAĞINIQ SKLEROZLU XəSTӘLӘRIN KLINIIK TəCRÜBӘSINNDə MULTIMODAL ÇAĞIRILMIŞ POTENSİALLARIN ANALIZİ}

\author{
Şirəliyeva R.K.*, Hüseynova S.K., Nosrullayeva N.A. \\ Akademik Z.Ә. Oliyeva adına Milli oftalmologiya morkəzi, Bakl; \\ *O. Oliyev adına Azarbaycan Dövlat Həkimlori Təkmillaşdirmə İnstitutunun \\ Sinir xastaliklari kafedrası, Bakı
}

Təqdim olunmuş işin məqsədi xəstəliyin başlanmasından keçən 3 il müddət ərzində dağınıq sklerozlu xəstələrdə çağırılmış potensialların məlumatlarının 3 və 6 ay aralığında dinamik təhlilinin həyata keçirilməsidir.Materiallar və metodlar. Bizim tərəfimizdən 65 xəstə (43 kişi və 22 qadın, orta yaş $26,6 \pm 3,7$ il) klinik və neyrofizioloji cəhətdən tədqiq olunmuşdur. 65 xəstədən 42-si (65\%) azalma anından 2 həftə müddətində təcrid olunmuş kəskin optik nefritlə (ON) daxil olmuşdu; bu zaman 9 xəstədə (14\%) ikitərəfli ON qeyd edilmişdi. 23 xəstə $(35 \%)$ dağınıq skleroz (DS) fonunda optik nefritlə daxil olmuşdu.Çağırılmış potensialların dinamik tədqiqinin nəticələrinin təhlili görmə çağırılmış potensiallarla (GÇP) müqayisədə akustik gövdə çağırılmış potensiallarının (AGÇP) və somatosensor çağırılmış potensiallarının (SSÇP) əhəmiyyətsiz dərəcədə dəyişməsindən və ya pisləşməsindən xəbər verirdi ki, bu da demielinizasiya prosesinin artmasını göstərirdi. Çağırılmış potensialların parametrlərinin aşkar edilmiş yaxşılaşmaları (müvafiq olaraq GÇP üçün 51\%, AGÇP üçün 23 \% və SSÇP üçün yalnız 17\%) cərəyan etməkdə olan remielinizasiya prosesindən xəbər verirdi.

Açar sözlər: dağınıq skleroz, çağrılmış potensiallar.

\section{SUMMARY}

\section{ANALYSIS OF MULTIMODAL EVOKED POTENTIALS IN CLINICAL PRACTICE IN PATIENTS WITH MULTIPLE SCLEROSIS}

\author{
Shiraliyeva R.K*., Guseynova S.K., Nasrullayeva N.A. \\ National Ophtalmology Center,named after akad.Z.Aliyeva, Baku; \\ *Azerbaijan State Advanced Training Institute for Doctors, Baku
}

The aim of this work is to carry out a dynamic analysis of evoked potentials in patients with multiple sclerosis in 3 and 6-month intervals for up to 3 years from the onset. Materials and methods. We conducted a comprehensive clinical and neurophysiologic study of 65 patients (43 women and 22 men, mean age 26, $6 \pm 3,7$ years). During dynamic examination acoustic evoked potentials (AEP) or somatosensory evoked potentials (SEP), the parameters or slightly changed, or given the deterioration, that is, the growth of demyelination. In a small percent of cases, compared with the dynamics of the visual evoked potentials (VEP), improvements in these parameters were observed and there were processes remyelination: respectively $52 \%$ for VEP, $23 \%$ for SEP and only $17 \%$ for AEP. Thus, more distinct remyelination process according to evoked potentials observed in the analysis of the visual pathways.

Key words: multiple sclerosis, evoked potentials. 